\title{
Alejo Carpentier, autor transcultural. El caso de El reino de este mundo
}

\author{
Isabel ARAÚJO BRANCO \\ Universidade Nova de Lisboa \\ isabelaraujobranco@gmail.com
}

\begin{abstract}
RESUMEN
El cubano Alejo Carpentier es un autor transcultural y, por tanto, entre culturas. Recupera estrategias literarias europeas para alcanzar su objetivo: retratar la esencia latinoamericana como nadie lo había hecho hasta entonces. Para ello desarrolla nuevos instrumentos, lo real maravilloso y el neobarroco. En este artículo pretendemos ver las estrategias transculturales de Carpentier y, bajo esa perspectiva, su representación de Latinoamérica en la novela El reino de este mundo. En ella, encontramos el subcontinente como un producto transcultural y un conjunto de personajes que representan ya ese nuevo mundo: Monsieur Lenormand de Mezy, Paulina y Henri Christophe. Mackandal, por su parte, encarna lo real maravilloso, recurso que es en sí mismo un producto transcultural.
\end{abstract}

Palabras clave: Alejo Carpentier, Latinoamérica, real maravilloso, neobarroco.

[Recibido, febrero 2012; aprobado, mayo 2012]

Alejo Carpentier, a cross-cultural author.
The case of El reino de este mundo

\begin{abstract}
The Cuban Alejo Carpentier is a cross-cultural author, writing between cultures. He takes European literary strategies in order to accomplish his aim: to depict the Latin American essence as no one had done before. To do so, he develops new instruments: the marvelous real and the neobarroque. In this article, we will consider Carpentier's transcultural strategies and, from this point of view, his representation of Latin America in the novel El reino de este mundo (The kingdom of this world). The novel presents the subcontinent as a transcultural product, and there is a group of characters who already represent the new world: Monsieur Lenormand de Mezy, Paulina and Henri Christophe. Mackandal, on the other hand, embodies the marvelous real, a strategy that is in itself a transcultural product.
\end{abstract}

Keywords: Alejo Carpentier, Latin America, marvelous real, neobarroque. 
El antropólogo cubano Fernando Ortiz propone, en Contrapunteo cubano del tabaco y el azúcar -editado primero en 1940 y nuevamente en 1963-, el concepto de transculturación, que nos será útil para analizar la obra literaria del igualmente cubano Alejo Carpentier, en particular su novela El reino de este mundo (1949). Con este concepto, Ortiz pretende reflejar las fases del proceso de transición de una cultura a otra: «éste no consiste solamente en adquirir una distinta cultura», sino que también conlleva «necesariamente la pérdida o desarraigo de una cultura precedente» (Ortiz 2002: 260). Tras las fases de aculturación y desculturación, surge la neoculturación, en que emergen nuevos fenómenos culturales: «en todo abrazo de culturas sucede lo que en la cópula genética de los individuos: la criatura siempre tiene algo de ambos progenitores, pero también siempre es distinta de cada uno de los dos.» (idem, ibidem) Según Ortiz, Cuba fue escenario de uno de los procesos de transculturación más intensos, desde el indígena paleolítico hasta la llegada de inmigrantes de todas las partes del mundo en los siglos más recientes, en procesos de desajuste y reajuste simultáneos.

Enrico Mario Santí sostiene que la transculturación es la «fuente secreta de gran parte de la teorización literaria que se ha hecho del Barroco contemporáneo latinoamericano» (Santí 2002: 101), presentando los ejemplos de Alejo Carpentier y José Lezama Lima como casos de asimilación del concepto en sus concepciones sobre el neobarroco, aunque sin reconocerlo:

Barroco en estas discusiones es el adjetivo o tropo que nombra la especificidad del mestizaje latinoamericano en reacción a la colonización europea, y no únicamente a la zaga de ella, que no es sino transculturación, según la define Ortiz: «las diferentes fases del proceso transitivo de una cultura a otra.» (Santí 2002: 102)

Sin embargo, encontramos testimonios de Carpentier sobre Ortiz, no sólo en relación a su acercamiento al Grupo Minorista (agrupamiento de que el escritor formaba parte en los años 1920), sino cuando habla sobre el «descubrimiento del negro» en la sociedad cubana por el antropólogo, en una época en que aquella cultura era totalmente menospreciada:

De don Fernando Ortiz, iniciador de lo que entonces hubo de llamarse «estudios afrocubanos» decían las gentes del «Yacht Club» y del «Tennis Club» de La Habana: «Parece mentira que un hombre con tanto talento pierda su tiempo estudiando semejantes cosas...» (Chao 1998: 284)

Pasemos al Prólogo de El reino de este mundo, en que Carpentier habla por primera vez de lo real maravilloso y afirma que pretende narrar «una sucesión de hechos extraordinarios, ocurridos en la isla de Santo Domingo, en determinada época que no alcanza el lapso de una vida humana, dejándose que lo maravilloso fluya libremente de una realidad estrictamente seguida en todos sus detalles», añadiendo que utilizó «una documentación extremamente rigurosa», respetando «la verdad histórica de los acontecimientos, los nombres de personajes [...], de lugares y hasta de calles», basándose aún en «un minucioso cotejo de fechas y cronologí- 
as» (Carpentier 2004: 14). Carpentier pretende, por tanto, reflejar la realidad latinoamericana en su literatura y, para ello, se basa en la realidad del subcontinente y utiliza lo real maravilloso y el neobarroco, instrumentos literarios que tienen sus raíces en Europa, respectivamente en el barroco español y en el surrealismo francés. Las propuestas de Carpentier son, así, ya resultados transculturales del encuentro de culturas diferentes $-y$ su obra se encuentra, pues, entre diferentes culturas-. Pasemos ahora a la novela.

El reino de este mundo se inicia con una presentación del mundo urbano del Caribe en los finales del siglo xviii, mostrando su variedad y contradicciones, los elementos de diferentes proveniencias y su convivencia. Acompañando a Ti Noel y a Monsieur Lenormand de Mezy, el lector recorre el puerto y la Calle Mayor, haciendo pausas en el peluquero y el librero, observando a la población de una ciudad cosmopolita, con gente y productos de Europa, África y otras regiones de Latinoamérica:

A las negras que regresaban del mercado, habían sucedido las señoras que salían de la misa de diez. Más de una cuarentona, barragana de algún funcionario enriquecido, se hacía seguir por una camarera de tan quebrado color como ella, que llevaba el abanico de palma, el breviario y el quitasol de borlas doradas. En una esquina bailaban los títeres de un bululú. Más adelante, un marinero ofrecía a las damas un monito del Brasil, vestido a la española. En las tabernas se descorchaban botellas de vino, refrescadas en barriles llenos de sal y de arena mojada. (Carpentier 2004: 24-25)

Las cortes europeas son ridiculizadas, en comparación con las africanas. Estas son dirigidas por un rey «guerrero, cazador, juez y sacerdote» (Carpentier 2004: 23), varonil y con muchas mujeres, padre de príncipes heroicos y poderosos, que dominaban la naturaleza y la fuerza. Los reyes europeos, por su parte, son cobardes y débiles: no combaten en las guerras, obedecen a sus confesores y conciben a hijos flacos.

Latinoamérica es, pues, presentada ya como una mezcla de diversos y distintos mundos -Europa, África y América-, componentes que al parecer son contradictorios y antagonistas, pero que se juntan aunque de forma no demasiado evidente. $\mathrm{El}$ reino de este mundo concede unidad a esos rasgos hasta hace poco distintos, la unidad transcultural de Latinoamérica.

¿Qué elementos europeos, africanos y americanos hallamos en la novela, qué elementos originaron el resultado transcultural que Latinoamérica constituye? De Europa, se evidencia la arquitectura y las ciudades, la ideología libertaria de la Revolución Francesa, la religión católica y el origen de las prácticas violentas. Pero la misma obra es fruto de ese intercambio transcultural, ya que el neobarroco y lo real maravilloso que la caracterizan tienen en el barroco español y en el surrealismo francés sus respectivos padres, como hemos visto. Pasemos a África: de ese continente encontramos la cultura, los mitos, la memoria, la religión, la fuerte resistencia a los colonos y a los personajes que dan cuerpo a lo real maravilloso. De América, tenemos la naturaleza fuerte y prodigiosa. 
Evidentemente Latinoamérica es mucho más que la suma de estos rasgos. Esta adición originó una transformación, una realidad que no existía anteriormente (cuando estos elementos estaban separados), el resultado transcultural de estos tres vectores. Dicho de otra manera: Latinoamérica no sería lo que es sólo con el cruce de elementos americanos y europeos, europeos y africanos o americanos y africanos. Para ser lo que es, hubo que juntar los tres elementos. Todos esos vectores están presentes en El reino de este mundo, obra que es, de alguna forma, un espejo del subcontinente. ¿Dónde más se podría encontrar negros bailando «fandangos de castañuelas» (Carpentier 2004: 42) y monos brasileños con prendas españolas? Hay que subrayar que este proceso está todavía en marcha, no está terminado y que, en la narrativa, no encontramos la relación armoniosa, que parece indicar el Prólogo. Hay, sí, conflictos y tensiones. Asimismo, no es perceptible en la novela la predominancia de un elemento sobre los restantes, sino la presencia más visible de alguno en determinados capítulos.

En la narrativa, lo que más se evidencia es la resistencia y la revuelta de los negros (africanos y descendentes de africanos, ya latinoamericanos) contra toda opresión: primero, la de los colonos blancos; luego, la del rey Henri Christophe. Ambos gobiernos no difieren mucho, utilizando la fuerza para explotar a la población. También las cortes y elites se comportan de forma semejante: parecen contemplar el mundo con sensibilidad e inteligencia, pero se establecen sobre una base de terror y violencia:

Ti Noel recibió un garrotazo en el cráneo. Sin objetar más, emprendió la ascensión de la empinada montaña, metiéndose en una larga fila de niños, de muchachas embarazadas, de mujeres y de ancianos, que también llevaban un ladrillo en la mano. [...] Un poco más lejos, el capellán de la reina - único de semblante claro en el cuadro - leía las Vidas paralelas de Plutarco al príncipe heredero, bajo la mirada complacida de Henri Christophe, que paseaba, seguido de sus ministros, por los jardines de la reina. De paso, Su Majestad agarraba distraídamente una rosa blanca, recién abierta sobre los bojes que perfilaban una corona y un ave fénix al pie de las alegorías de mármol. (Carpentier 2004: 103-104)

Esta nueva sociedad liderada por Henri Christophe era, de hecho, «un mundo de negros» (Carpentier 2004: 102), como concluye, pasmado, Ti Noel, donde hasta la imagen de la Virgen en la iglesia es negra. Pero, más allá del color, todo permanece igual que en el tiempo de los colonos europeos: las jerarquías, la explotación, la pobreza, la desigualdad y la injusticia. Una injusticia todavía más escandalosa, en la opinión del personaje, porque todos son negros:

[...] una esclavitud tan abominable como la que había conocido en la hacienda de Monsieur Lenormand de Mezy. Peor aún, puesto que había una infinita miseria en lo de verse apaleado por un negro, tan negro como uno, tan belfudo y pelicrespo, tan nariznato como uno [...]. Era como si en una misma casa los hijos pegaran a los padres, el nieto a la abuela, las nueras a la madre que cocinaba. (Carpentier 2004: 108) 
La revuelta contra el nuevo señor surge poco después. La divisa del blasón que representa un fénix en una sala del palacio puede ser tomada, pues, como símbolo de la población: «Renazco de mis cenizas.» (Carpentier 2004: 126). Siempre hay un nuevo recomenzar, un nuevo momento de revuelta ante la opresión. Porque, como leemos en el último capítulo de la novela, «la grandeza del hombre está precisamente en querer mejorar lo que es. En imponerse Tareas.» (Carpentier 2004: 156). Ello solo es posible de alcanzar en la Tierra, vivos, no en el Reino de los Cielos: «el hombre sólo puede hallar su grandeza, su máxima medida en el Reino de este Mundo» (idem, ibidem).

Como indica el mismo título, esta lucha constituye el tema central de la novela, una lucha que se va perpetuando. El final feliz jamás es definitivo. Primero, tenemos una colonia donde los negros son explotados como esclavos. Mackandal surge con sus poderes, los organiza, se sublevan y vencen a los colonos, pero la república de los negros no se implanta. El final feliz es aplazado. Más tarde, el país pasa a ser gobernado por un negro, pero la población sigue siendo violentada y explotada. Otro final feliz pospuesto.

Algunos personajes de El reino de este mundo son como representaciones de uno de los mundos de origen que acaban por revelarse una mezcla, un resultado transcultural latinoamericano. En primer lugar, tenemos Monsieur Lenormand de Mezy, que, cuando enviuda, vuelve a París. Con todo, pasa «algo muy sorprendente»:

[...] al cabo de pocos meses, una creciente nostalgia de sol, de espacio, de abundancia, de señorío, de negras tumbadas a la orilla de una cañada, le habían revelado que ese «regreso a Francia», para el cual había estado trabajando durante largos años, no era ya, para él, la clave de la felicidad. (Carpentier 2004: 57)

Él echa de menos América, al final más suya que las tierras de Francia o, en otras palabras, es ya más americano que francés. Él se identifica, sí, con el clima, el paisaje y las gentes americanas.

Paulina Bonaparte, corsa de nacimiento, descubre con placer el Caribe, comprendido como una especie de cielo en la tierra: "Sintiéndose algo ave del paraíso, algo pájaro lira, bajo sus faldas de muselina, descubría la finura de helechos nuevos, la parda jugosidad de los nísperos, el tamaño de hojas que podían doblarse como abanicos" (Carpentier 2004: 83). De tanto sol que toma, la piel de Paulina oscurece, al punto de parecerse a una «espléndida mulata» (Carpentier 2004: 86). Este cambio en su piel no es secundario, ya que se trata de un órgano complejo que abarca todo el cuerpo. Es una transformación física que alcanza todo su ser. No es una simple mudanza voluntaria de peinado, es algo mucho más profundo. Debido a su sangre corsa, ella se siente cerca de las divinidades africanas y, cuando su marido enferma, recurre a ellas con una fe fervorosa, acompañando al esclavo Solimón en las prácticas religiosas. Con la muerte de su marido, Paulina regresa a Europa ya otra: consigo lleva un amuleto a Papá Legba, arreglado por su siervo con el objetivo de abrirle «todos los caminos que la condujeron a Roma» (Carpentier 2004: 90).

Finalmente, Henri Christophe es negro, pero asume la estética europea: ordena la construcción de un palacio y una fortaleza a la imagen de las francesas, escucha 
lecturas de autores de la Antigua Grecia, practica la religión católica, se afirma rey y constituye una corte con reina, princesas, ministros y pajes. ¿Qué diferencia a Henri Christophe de los monarcas europeos? Simplemente su origen y el color de su piel.

Pasemos a otro personaje, que asume un rol central en la obra: Mackandal. Referido ya en el primero capítulo y presentado en el segundo, Mackandal es un hombre que atrae a los demás, conocido por sus narrativas y memorias. Contaba su antigua vida en Guinea y comparaba las magníficas prácticas de África con la pobreza de la sociedad colonial y las prácticas europeas. Tras perder un brazo en un accidente, se hace pastor y empieza a interesarse por flora y fauna de forma particular:

Descubría, con sorpresa, la vida secreta de especies singulares, afectas al disfraz, la confusión, el verde verde, y amigas de la pequeña gente acorazada que esquivaba los caminos de hormigas. (Carpentier 2004: 29)

Poco a poco, descubre nuevos poderes y proclama una cruzada contra los colonos blancos, proponiéndose crear un imperio de negros libres. Los esclavos se unen a él, rendidos a su capacidad de convertirse en el animal o planta que desee:

Todos sabían que la iguana verde, la mariposa nocturna, el perro desconocido, el alcatraz inverosímil, no eran sino simples disfraces. Dotado del poder de transformarse en animal de pezuña, en ave, pez o insecto, Mackandal visitaba continuamente las haciendas de la Llanura [...]. De metamorfosis en metamorfosis, el manco estaba en todas partes, habiendo recobrado su integridad corpórea al vestir trajes de animales. Con alas un día, con agallas al otro, galopando o reptando, se había adueñado del curso de los ríos subterráneos, de las cavernas de la costa, de las copas de los árboles, y reinaba ya sobre la isla entera. Ahora, sus poderes eran ilimitados. (Carpentier 2004: 43).

Tenemos aquí, por tanto, lo real maravilloso, en su plenitud. Recuperemos las palabras de Alejo Carpentier en el Prólogo, cuando afirmaba que, en Haití, había entrado en «contacto cotidiano con algo que podríamos llamar lo real maravilloso»:

Pisaba yo una tierra donde millares de hombres ansiosos de libertad creyeron en los poderes licantrópicos de Mackandal, a punto de que esa fe colectiva produjera un milagro el día de su ejecución. [...] A cada paso hallaba lo real maravilloso. Pero pensaba, además, que esa presencia y vigencia de lo real maravilloso no era privilegio único de Haití, sino patrimonio de la América entera [...]. Lo real maravilloso se encuentra a cada paso en las vidas de hombres que inscribieron fechas en la historia del Continente y dejaron apellidos aún llevados. $[\ldots]$

[...] por la virginidad del paisaje, por la formación, por la ontología, por la presencia fáustica del indio y del negro, por la Revolución que constituyó su reciente descubrimiento por los fecundos mestizajes que propició, América está muy lejos de haber agotado su caudal de mitologías. (Carpentier 2004: 11) 
Mackandal es la expresión máxima de ese real maravilloso: «Mackandal Hombre. El Manco. El Restituido. El Acontecido.» (Carpentier 2004: 156) Sus facciones cambian bajo influencia de los animales en que se convierte impresionando a todos los que lo ven. En el día de su ejecución, huye de los soldados, mezclándose en la muchedumbre, pero acaban por agarrarlo y matarlo. Permanece, sin embargo, en la memoria del pueblo. Ti Noel narra sus hazañas, repite sus cuentos y compone canciones en que lo glorifica, aguardando su regreso: «el Manco, alejado de estas tierras por tareas de importancia, regresaría a ellas el día menos pensado.» (Carpentier 2004: 59). El recuerdo se mantiene a lo largo de los años, pero se vuelve más vívido cuando Ti Noel adquiere también él la capacidad de convertir su cuerpo en otras formas: ave, caballo, avispa, hormiga y ganso. El paso siguiente es declarar la guerra a los nuevos amos. Como, por cierto, había hecho años antes Mackandal, su modelo. Y en la Tierra, sin posponer nada para el cielo, o sea, en el «reino de este mundo».

\section{Referencias bibliográficas}

CARPENTIER, Alejo (2004): El reino de este mundo. Madrid: Alianza Editorial. CHAO, Ramón (1998): Conversaciones con Alejo Carpentier. Madrid: Alianza Editorial.

ORTIZ, Fernando (2002): Contrapunteo cubano del tabaco y el azúcar. Madrid: Cátedra.

SANTÍ, Enrico Mario (2002): «Fernando Ortiz: Contrapunteo y transculturación» in ORTIZ, Fernando, Contrapunteo cubano del tabaco y el azúcar. Madrid: Cátedra. 